\title{
Evaluation of Single-use Tangential Flow Filtration Technology for Purification of Activated Polysaccharides Used in Conjugate Vaccine Manufacturing
}

\author{
Seyed Pouria Motevalian ${ }^{1}$, Jonathan Steen ${ }^{2}$, Janine De Leon ${ }^{1}$, Verl Sriskanda ${ }^{1}$, Ivette \\ Carino $^{1}$, Amar Prashad ${ }^{1}$, Brenda Carillo Conde ${ }^{1}$, and Bo Arve ${ }^{1}$ \\ ${ }^{1}$ Pfizer Global Pharmaceuticals \\ ${ }^{2}$ MilliporeSigma
}

May 13, 2021

\begin{abstract}
Over the past decade, single-use tangential flow filtration (TFF) technologies have emerged to reduce system preparation time, promote fast and flexible product change over, and ultimately shorten process development and manufacturing time/cost. In this study, the performance of a recently developed Pellicon@ single-use TFF capsule was compared against traditional Pellicon $\AA$ cassette by assessing TFF process performance (such as flux, residuals clearance, and yield) and post-purification product attributes (such as concentration and mass-weighted average molecular weight). Good scaling was shown by comparing process performance and product attributes across different scales and formats. Additionally, similar TFF process performance and post-purification product attributes were observed for the single-use capsule compared to the reusable TFF cassettes. The capsule requires a smaller flush than the cassette, and it is easier to use since it does not require a compression holder or pre-sanitization. The results provide insight into the application of the single-use TFF capsule and scalability of TFF processes for the purification of conjugate vaccines.
\end{abstract}

\section{Hosted file}

SUTFF-Manuscript-Biotech-Bioeng.pdf available at https://authorea.com/users/413673/articles/ 521921-evaluation-of-single-use-tangential-flow-filtration-technology-for-purificationof-activated-polysaccharides-used-in-conjugate-vaccine-manufacturing

\section{Hosted file}

Tables.pdf available at https://authorea.com/users/413673/articles/521921-evaluationof-single-use-tangential-flow-filtration-technology-for-purification-of-activatedpolysaccharides-used-in-conjugate-vaccine-manufacturing 

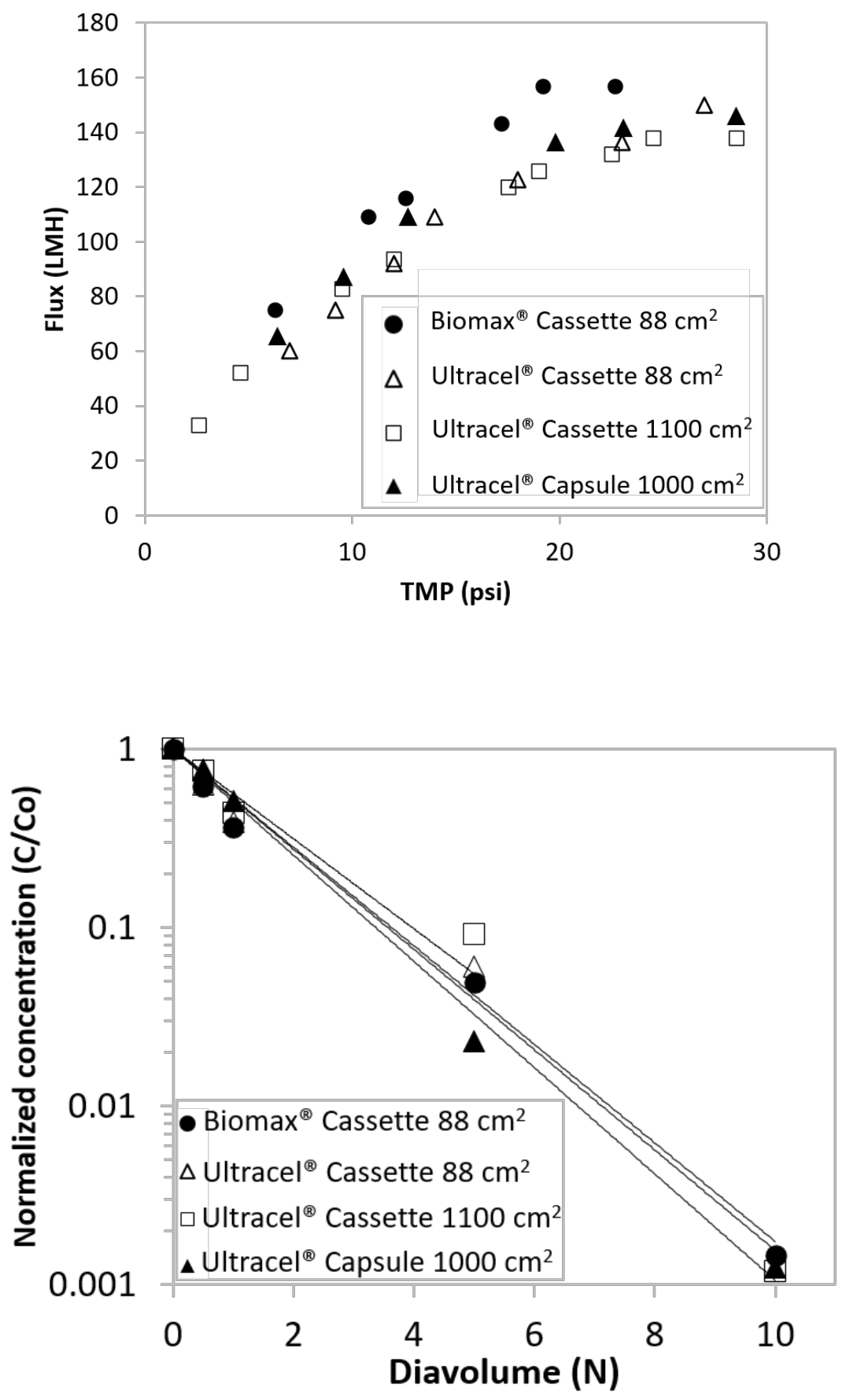

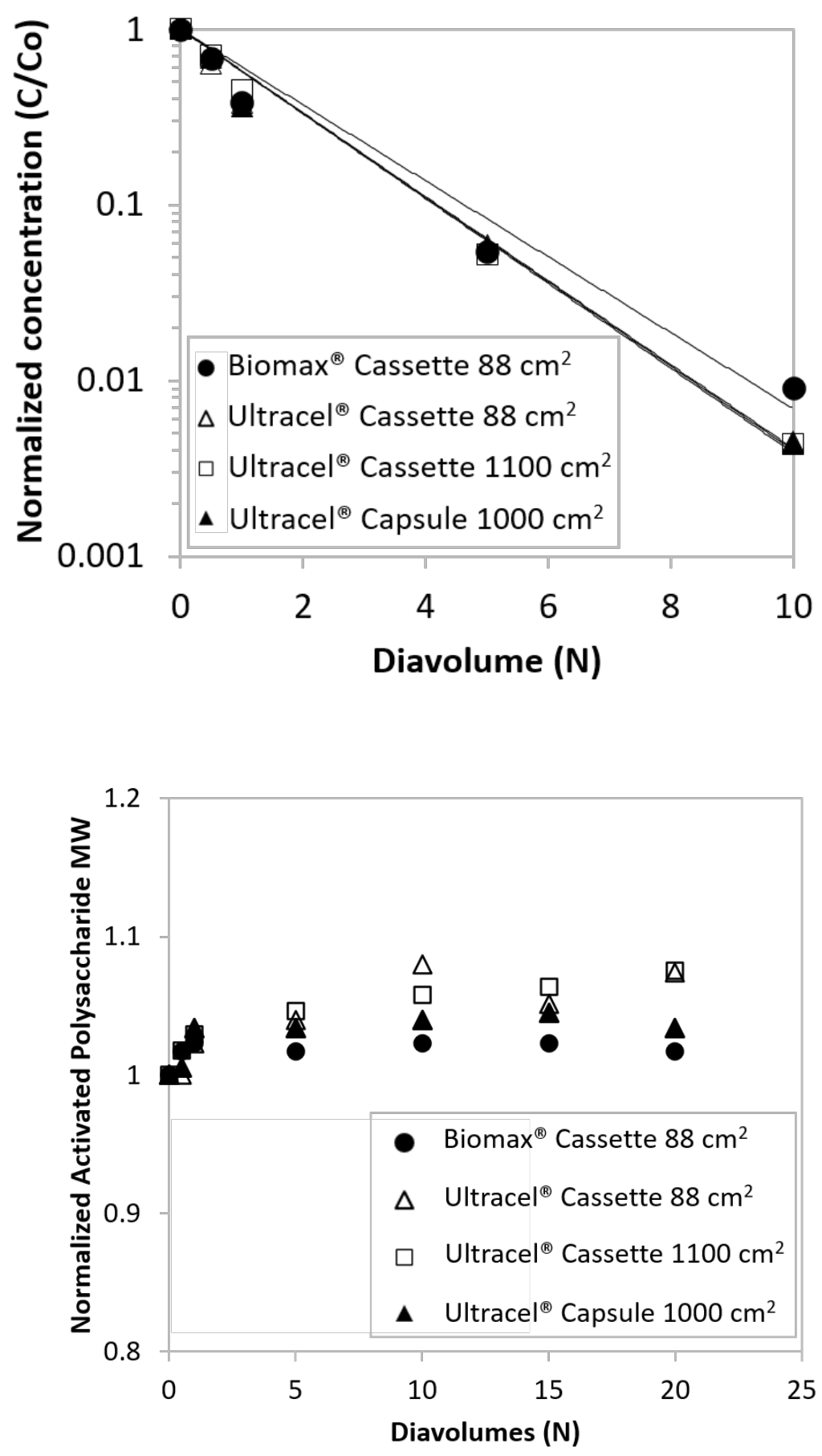


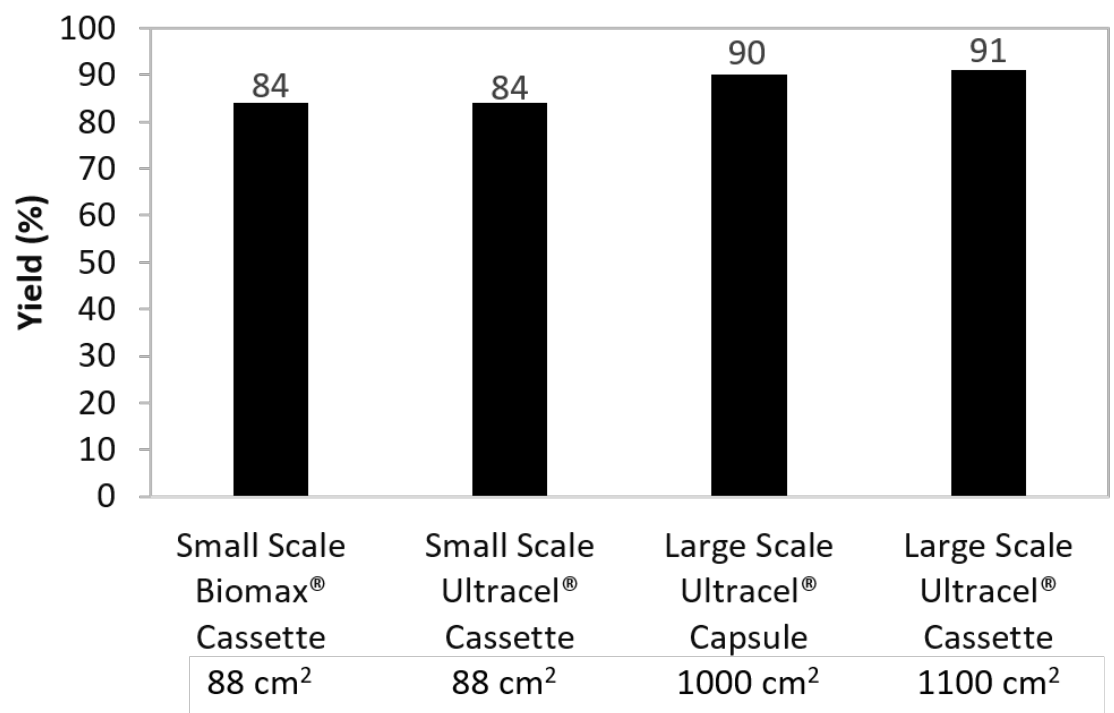

